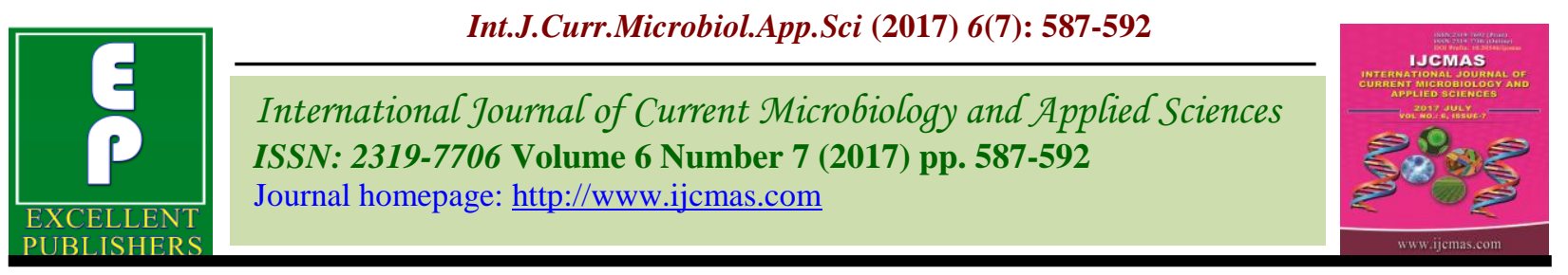

Original Research Article

https://doi.org/10.20546/ijcmas.2017.607.071

\title{
Estimation and Forecasting of Chickpea Production by Structural Time-Series Modelling
}

\author{
Roshan Kumar Bhardwaj ${ }^{\text {** }}$, Vandana Bhardwaj' ${ }^{2}$ D.P. Singh ${ }^{1}$, S.S. Gautam ${ }^{3}$, \\ R.R. Saxena ${ }^{4}$ and Gaurav Jatav ${ }^{4}$ \\ ${ }^{1}$ Agriculture Statistics, M.G.C.G.V, Chitrakoot, Satna (M.P.), India \\ ${ }^{2}$ Department in Education, Panchayat, Surguja (CG), India \\ ${ }^{3}$ Statistics Department of Physical Science, M.G.C.G.V, Chitrakoot, Satna (M.P.), India \\ ${ }^{4}$ Department of Agriculture Statistics and SSL, I.G.K.V., Raipur (C.G.), India \\ *Corresponding author
}

\begin{abstract}
Keywords
AIC, BIC,

Goodness of fit,

Forecasting,

Modelling and

structural time

series model.

Article Info

Accepted:

14 June 2017

Available Online:

10 July 2017 time-series data in the present of trend, seasonal and cyclic fluctuations. Structural time series model are formulated in such a way that their components are stochastic, i.e. they are regard as being driven by random disturbances. Structural time series model are formulated in such a way that their components are stochastic, i.e. they are regard as being driven by random disturbances. The study mainly confined to secondary collected data from a period 2009-10 to 2014-15 data of promising varieties of chickpea yield. As these techniques, it may be mentioned that models are fitted to the data and coefficient parameter value obtained on the basis of the model are compared with the actual observation for assessing the accuracy of the fitted model. To validate the forecasting ability of the fitted models, for the three years with upper and lower limit. The maximum chickpea yield obtained consistently JG-11variety with forecast for the year 201718 obtained $15.36 \mathrm{q} / \mathrm{ha}$ and the minimum yield obtained with decreasing order are Vijay and JG-6.
\end{abstract}

\section{A B S T R A C T}

Purpose of present paper is to discuss STM methodology utilized for modelling

\section{Introduction}

ARIMA time series methodology is widely used for modelling time series data. Statistical modelling of time-series data in Agriculture is usually carried out by employing ARIMA methodology (Brockwell and Davis, 1991).This methodology can be applied only when either the series under consideration is stationary or it can be made so by differencing, de-trending, or by any other means. Another disadvantage is that this approach is empirical in nature and does not provide any insight into the fundamental mechanism. An alternative mechanistic approach, which is quite promising, is the "Structural time series modeling (Harvey, 1996)". A quite promising, mechanistic approach, which does not suffer from this drawback, is "Structural time-series modelling [(STSM)" Harvey]. The distinguishing feature of this methodology is that observations are 
regarded as made up of distinct components such as trend and cyclical fluctuations and each of which is modeled separately. The techniques that emerge from this approach are extremely flexible and are capable of handling a much wider range of problems than is possible through ARIMA approach. The Akaike Information Criterion (AIC) is a measure of the relative quality of statistical models for a given set of data. Given a collection of models for the data, AIC estimates the quality of each model, relative to each of the other models. Hence, AIC provides a means for model selection. BIC is an estimate of a function of the posterior probability of a model being true, under a certain Bayesian setup, so that a lower BIC means that a model is considered to be more likely to be the true model. Once a model is estimated, its suitability can be assessed using goodness fit statistics.

Promising variety is a popular variety and being cultivated widely. It may be a variety, an advance line, strain or land race (recommended or non-recommended). However, variety is a group of plants having distinct, uniform and stable traits which has been recommended for cultivation by a committee. There are many promising varieties of rice, are available but it depends on cultivation practices and geographical areas where some specific varieties are more suitable for its better production (Bharadwaj et al., 2015a,b; Bhardwaj et al., 2016).

Rice is an important crop grown in nearly 44 million ha of land in the country with the yield of $2.2 \mathrm{t} / \mathrm{ha}$ which is less than the productivity of many countries. Annual population growth rate of the country is nearly $1.8 \%$ and if per capita consumption of rice is expected to be $400 \mathrm{gm}$ of rice per day then the demand for rice in 2025 will be 130 m. tonnes. In Chhattisgarh, rice occupies average of 3.6 million ha. With the yield of the state ranging between 1.2-1.6 t/ha is depending upon the rainfall (Pandey, 2013). Though the yield of rice in the state is lowerthan the national average but high yielding varieties in the state is higher than the state yield as well as national yield which is ranging between 3.9 to 4.9 t/ha.

\section{Materials and Methods}

The study mainly confined to secondary collected for a period 2009-10 to 2014-15 data of promising varieties of Rice yield. Data collected from various publications, Government of Chhattisgarh were subjected structural time series model. The data are analyzed by using software Statistical Analysis System (SAS). Structural time series model adopted for forecasting purpose is given below.

\section{Structural time series model for trend}

A structural time series model is set up in term of its various components, like trend, cyclic fluctuations and seasonal variation, i.e.

$Y_{t}=T_{t}+C_{t}+S_{t}+\varepsilon_{t}(1)$

Where ${ }_{\mathrm{Yt}}$ is the observed time-series at time $\mathrm{t}$, $\mathrm{T}_{\mathrm{t}}, \mathrm{C}_{\mathrm{t}}, \mathrm{S}_{\mathrm{t}}, \varepsilon_{\mathrm{t}}$ are the trend, cyclical, seasonal and irregular components.

\section{Local Level Model (LLM)}

In the absence of seasonal and cyclical components, eq. (1) reduce to

$\mathrm{Y}_{\mathrm{t}}=\mu_{\mathrm{t}}+\varepsilon_{\mathrm{t}}, \varepsilon_{\mathrm{t}} \sim \mathrm{N}\left(0, \sigma_{\varepsilon}{ }^{2}\right), \mathrm{t}=1,2 \ldots \mathrm{T}(2)$

Where $\mu_{\mathrm{t}}=\mu_{\mathrm{t}-1}+\beta_{\mathrm{t}-1}+\eta_{\mathrm{t}}$ and $\beta_{\mathrm{t}}=\beta_{\mathrm{t}-1}+\varepsilon_{\mathrm{t}}$

\section{Goodness of fit}

Goodness of fit statistics is used for assessing over all models fit. Basic measure of 
goodness of fit in time series model is prediction error variance. Comparison of fit between different models is based on Akaike information criterion (AIC).

$\mathrm{AIC}=-2 \log \mathrm{L}+2 \mathrm{n},(3)$

Where $\mathrm{L}$ is the likelihood function, which is expressed in term of estimated one-step-ahead prediction errors $\mathrm{u} t=\mathrm{Yt}-\hat{\mathrm{Y}} \mathrm{t} / \mathrm{t}-1$.

Here $\mathrm{n}$ is the number of hyper parameters estimated from the model.

\section{Corrected criterion AIC (CAIC)}

It could be argued that a good model selection criterion should work even if the user tries a "bad" (e.g., over-parameterized) model: If the model is bad, the criterion should be able to detect this. In this regard, AIC fails. In order to remove this deficiency, the normal multiple regression model for small samples, we can define the finite sample corrected AIC, namely, originally proposed by Sugiura (1978) and later used Hurvich and Tsai (1989) introduced a corrected version, CAIC, defined by

CAIC $=n \log (2 \pi)+n \log \left(\hat{\sigma}^{2}\right)+n+2 \frac{n(k+1)}{n-k-2}$,

\section{Consistent AIC (AICC)}

We recommend the use of the AIC and not the AICC for analysis and inference from capture-recapture data sets. It is proposed by Bozdogan (1987) and represented by

$\mathrm{AICC}=-2 \log \mathrm{L}+\mathrm{n}((\log \mathrm{T})+1)$

The lower values of these statistics, better is the fitted model.

\section{Schwartz-Bayesian information criterion}

(SBC, Schwartz, 1978) is also used as a measure of goodness of fit which is given as
$\mathrm{SBC}(\mathrm{BIC})=-2 \log \mathrm{L}+\mathrm{n} \log \mathrm{T}$,

Where, $\mathrm{T}$ is the total number of observations.

\section{Hannan-Quinn Information Criterion (HQIC)}

The Hannan-Quinn (1979) information criterion (HQIC) is a criterion for model selection. It is an alternative to Akaike information criterion (AIC) and Bayesian information criterion (BIC). It is given as

HQIC $=-2 \mathrm{~L}_{\max }+2 \mathrm{k} \log (\log \mathrm{n})$

\section{Software for STM modelling}

STM models can be fitted to the data using Structural Time-series Analyser, Modeller and Predictor (STAMP) (Koopman et al., 2000) or by using SsfPack 2.2 (Koopman et al., 1999) software package or by SAS (Statistical Analysis System), Version 9.2 software packages. The use of STAMP (Structural Time Series Analyser, Modeler and Predictor) for modeling time series data using state-space methods with un-observed components.

There are two important points to consider in modeling time series, the first is how well the model explains (or fits) the actual data of the production, and the other is how good the model forecasts the yield after a year or two or three.

\section{Results and Discussion}

Modeling yield trends through structural time series (STM)

Structural time series model were fitted for trend information and yield forecast of chickpea. To judge the forecasting ability of the fitted model, important measures of the three years forecast were computed. 
Structural time series model for chickpea crop

According to Likelihood statistics i.e., AIC, AICC, CAIC, HQIC, and BIC were calculated for different varieties of chickpea crop. Low values were found for chickpea JG-14 and JG-11 among all varieties (Table 1). Trend Information provided on the basis of level of small standard error for chickpea varieties; Vaibhav (0.002), JG-14 (0.228), JG-11 (0.287) and JG-226 (0.785) (Table 2).
Moreover, chickpea variety Vijay had standard error (0.003). The yield (q/ha) forecast for different varieties of chickpea showed that Vaibhav and Vishal had higher yield for next three (2015-16 to 2017-18) years, followed by JG-11, JG-16, JG-63, JG74, JG-226 and JAKI-9218, also showed increase in consistent order. Varieties of chickpea Vijay, JG-6, JG-14 and JG-130 showed decreasing yield for next upcoming years (Table 3) (Singh et al., 2014).

Table.1 Likelihood based fit statistics in varieties of chickpea crop

\begin{tabular}{|l|c|c|c|c|c|}
\hline Varieties & AIC & BIC & AICC & HQIC & CAIC \\
\hline Vijay & 26.26 & 24.42 & 44.26 & 22.22 & 27.42 \\
\hline JG-6 & 27.28 & 25.44 & 24.45 & 23.24 & 28.44 \\
\hline JG-11 & 18.13 & 16.29 & 36.13 & 14.09 & 19.29 \\
\hline JG-14 & 13.73 & 11.89 & 31.73 & 9.69 & 14.89 \\
\hline JG-16 & 27.84 & 26.00 & 45.84 & 23.80 & 29.00 \\
\hline JG-63 & 28.49 & 26.65 & 46.49 & 24.45 & 29.65 \\
\hline JG-74 & 24.74 & 22.90 & 42.74 & 20.70 & 25.90 \\
\hline JG-130 & 29.04 & 27.20 & 47.04 & 25.00 & 30.20 \\
\hline JG-226 & 22.66 & 20.82 & 40.66 & 18.62 & 23.82 \\
\hline Vaibhav & 22.05 & 20.21 & 40.05 & 18.05 & 23.21 \\
\hline JAKI-9218 & 21.96 & 20.12 & 39.96 & 17.92 & 23.12 \\
\hline Vishal & 25.12 & 23.28 & 43.12 & 21.08 & 26.28 \\
\hline
\end{tabular}

Smaller is better for AIC, BIC, AICC, HQIC and CAIC.

Table. 2 Trend Information (based on the final state) for different varieties of chickpea crop

\begin{tabular}{|l|c|c|c|c|}
\hline \multirow{2}{*}{ Varieties } & \multicolumn{3}{|c|}{ Components } \\
\cline { 2 - 5 } & \multicolumn{3}{|c|}{ Level } & Slope \\
\cline { 2 - 5 } & Estimate & Standard Error & Estimate & Standard Error \\
\hline Vijay & 11.67 & 0.003 & -0.064 & 1.114 \\
\hline JG-6 & 10.17 & 1.400 & 0.783 & 0.462 \\
\hline JG-11 & 14.99 & 0.287 & 0.121 & 0.945 \\
\hline JG-14 & 10.81 & 0.228 & -0.201 & 0.168 \\
\hline JG-16 & 13.19 & 1.500 & 0.327 & 0.496 \\
\hline JG-63 & 14.97 & 1.628 & 0.619 & 0.538 \\
\hline JG-74 & 16.38 & 1.090 & 0.396 & 0.336 \\
\hline JG-130 & 10.75 & 1.741 & -0.488 & 0.823 \\
\hline JG-226 & 14.30 & 0.785 & 0.341 & 0.259 \\
\hline Vaibhav & 15.98 & 0.002 & 3.989 & 1.800 \\
\hline JAKI-9218 & 13.20 & 0.719 & 0.429 & 0.237 \\
\hline Vishal & 15.71 & 1.089 & 1.640 & 1.580 \\
\hline
\end{tabular}


Table.3 Forecast of yield ( $\mathrm{q} / \mathrm{ha}$ ) of chickpea varieties from 2015-16 to 2017-18 in Chhattisgarh state

\begin{tabular}{|l|c|c|c|c|c|c|}
\hline & \multicolumn{2}{|c|}{$\mathbf{2 0 1 5 - 1 6}$} & \multicolumn{2}{c|}{$\mathbf{2 0 1 6 - 1 7}$} & \multicolumn{2}{c|}{$\mathbf{2 0 1 7 - 1 8}$} \\
\hline \multicolumn{1}{|c|}{ Variety } & Forecast & $\begin{array}{c}\text { Standard } \\
\text { Error }\end{array}$ & Forecast & $\begin{array}{c}\text { Standard } \\
\text { Error }\end{array}$ & Forecast & $\begin{array}{c}\text { Standard } \\
\text { Error }\end{array}$ \\
\hline Vijay & 11.61 & 2.72 & 11.55 & 4.16 & 11.48 & 5.45 \\
\hline JG-6 & 9.39 & 2.64 & 8.61 & 2.95 & 7.82 & 3.29 \\
\hline JG-11 & 15.11 & 1.09 & 15.24 & 2.18 & 15.36 & 3.53 \\
\hline JG-14 & 10.61 & 0.53 & 10.41 & 0.71 & 10.20 & 0.89 \\
\hline JG-16 & 13.52 & 2.83 & 13.84 & 3.16 & 14.17 & 3.53 \\
\hline JG-63 & 15.59 & 3.07 & 16.21 & 3.43 & 16.83 & 3.82 \\
\hline JG-74 & 16.78 & 1.92 & 17.17 & 2.14 & 17.57 & 2.39 \\
\hline JG-130 & 10.26 & 3.45 & 9.77 & 4.16 & 9.29 & 4.91 \\
\hline JG-226 & 14.64 & 1.48 & 14.99 & 1.65 & 15.33 & 1.84 \\
\hline Vaibhav & 19.97 & 1.80 & 23.96 & 4.02 & 27.95 & 6.73 \\
\hline JAKI-9218 & 13.63 & 1.35 & 14.06 & 1.51 & 14.49 & 1.69 \\
\hline Vishal & 17.36 & 2.34 & 19.00 & 3.38 & 20.64 & 4.70 \\
\hline
\end{tabular}

In conclusion, overall the class of models proposed introduces periodicity without affecting the possibility of extracting signals that are an expression the long run behavior. Therefore, they furnish a reasonable compromise between increasing model complexity in the presence of strong seasonal effects, and preserving the decomposability of the time series. In our study the structural time-series model developed for wheat yield comparison of the state yield showed that the yields of high yielding variety are GW-273 for state. This indicates that the promotion of high yielding varieties can be made for improving the overall productivity of the state.

\section{References}

Bozdogan, H., (1987). Model selection and Akaike's Information Criterion (AIC): The general theory and its analytical extensions. Psychometrika, 52, 345370.

Brockwell, P.I. and Davis, R.A. Time Series: Theory and Methods. 2nd edn, Springer Verlag, U.S.A. 1991.
Hannan, E. J., and Quinn, B. G., (1979). The Determination of the order of an auto regression. Journal of the Royal Statistical Society, Series B, 41, 190195.

Harvey A C. Forecasting, Structural Time Series Models and the Kalman Filter. Cambridge Univ. Press, U.K. 1996.

Hurvich Clifford M. and Tsai Chih-Ling, (1989). Bias of the corrected AIC criterion for under fitted regression and time series models. Biometrika: 78, 3, pp. 499-509.

Koopman S.J., Harvey, A.C., Doornik, J.A., and Shephard, N. (2000), STAMP 6.0. Structural Time Series Analyser, Modeller and Predictor. London, Timberlake Consultants Press, London.

Koopman S.J., Shepard, N., and Doornik, J.A. (1999), "Statistical algorithms for models in state space using SsfPack 2.2", Econometrics Journal, 2, 113-166.

Pandey, M.P., Varulkar, S.B. and Sarawagi, A.K. 2013.Status paper on rice in Chhattisgarh, pp 1-32.

Roshan Kumar Bharadwaj, S.S. Gautam and R.R. Saxena, 2015 (a). Structural Time- 
Series Models for Forecasting Yield of Promising Varieties of Rice Crop in Chhattisgarh. International Journal of Mathematics Trends and TechnologyVolume26 Number2 - October 2015. Pp: 58-62.

Roshan Kumar Bharadwaj, S.S. Gautam and R.R. Saxena. 2015 (b). Structural timeseries models for forecasting yield of promising varieties of wheat crop in Chhattisgarh. Trends Biosciences. 8(21): 5994-5997.

Roshan Kumar Bhardwaj, S. S. Gautam and R. R. Saxena, 2016. Structural timeseries models for forecasting yield of promising varieties of gram (chickpea) crop in Chhattisgarh. International Journal of Agricultural Science and Research (IJASR).

Ravichandran, S. and Prajneshu "State Space Modelling Versus ARIMA Time-Series Modelling". Jour. Ind. Soc. Ag.
Statistics. 54 (1): 43-51, 2000.

Ravichandran, S.and Prajneshu. "Dynamical modeling and forecasting of India's food grain production". Proc. Nat. Acad. Sci. India, Vol. 72, B (I), 2002.

Schwartz, G., (1978). Estimating the dimension of a model. Annals of Statistics, 6, 461-464.

Singh D.P., Thakur A. K. And Ram D.S., 2014. Application of Structural Time Series model for forecasting Gram production in India. American International Journal of Research in Science, Technology, Engineering \& Mathematics.

Sugiura, N., (1978). Further analysis of the data by Akaike's information criterion and the finite corrections. Communications in Statistics, Theory and Methods, A7, 13-26.

\section{How to cite this article:}

Roshan Kumar Bhardwaj, Vandana Bhardwaj, D.P. Singh, S.S. Gautam, R.R. Saxena and Gaurav Jatav. 2017. Estimation and Forecasting of Chickpea Production by Structural TimeSeries Modelling. Int.J.Curr.Microbiol.App.Sci. 6(7): 587-592. doi: https://doi.org/10.20546/ijcmas.2017.607.071 